\title{
miR-206 as a prognostic and sensitivity biomarker for platinum chemotherapy in epithelial ovarian cancer
}

Xiaotang Yu ${ }^{1} \mathbb{D}$, Xinchen Zhang ${ }^{2}$, Guang Wang ${ }^{2}$, Bo Wang ${ }^{1}$, Yanfang Ding ${ }^{2}$, Jinyao Zhao ${ }^{3}$, Hanlin Liu² and Shiying $\mathrm{Cui}^{\mathrm{i}^{*}}$ (D)

\begin{abstract}
Background: Drug resistance is a major obstacle to successful chemotherapy for epithelial ovarian cancer (EOC). We found a subset of miRNAs associated with the response to first-line platinum-based chemotherapy in EOC by microarray, and miR-206 was one of the most significant miRNAs. The purposes of this study were to evaluate the prognostic and platinum-resistance predictive value of miR-206 in EOC patients and to investigate the functional roles of miR-206 in regulating the platinum resistance of EOC and the underlying mechanism.
\end{abstract}

Methods: MiRNA expression profiling in EOC specimens was performed using a TaqMan miRNA array. miR-206 expression was confirmed by quantitative real-time PCR (qRT-PCR) analysis. Overexpression of miR-206 in EOC cell lines was achieved by the stable transfection of a recombinant plasmid. In vitro assays of cisplatin cytotoxicity, cell cycle distribution, apoptosis, transwell invasion and cell scratching were employed. Connexin 43 (Cx43) expression was detected by Western blotting. Murine xenograft models were used to determine the effects of miR-206 on platinum resistance in vivo.

Results: miR-206 expression was increased in primary platinum-resistant EOC. High miR-206 expression was related to poor prognosis in EOC patients who received platinum-based chemotherapy and predicted chemoresistance to platinum treatment. Overexpression of miR-206 in cisplatin-sensitive EOC cell lines significantly increased cell viability, migration and invasion in the presence of cisplatin and decreased cisplatin-induced apoptosis. Cx43, a target gene of miR-206, was negatively regulated by miR-206 in EOC cell lines and significantly related to better prognosis in patients who received platinum-based chemotherapy (KmPlot). miR-206 had high expression and Cx43 had low expression in platinum-sensitive EOC cell lines compared with resistant ones. In vivo murine xenograft models showed that miR206 profoundly promoted the chemoresistance of EOC to cisplatin treatment.

Conclusion: miR-206 was highly expressed in primary platinum-resistant EOCs and functionally promoted platinum resistance in part by downregulating Cx43 expression, thereby providing a useful biomarker for prognostic and platinum-resistance prediction.

Keywords: Epithelial ovarian cancer, Platinum, Chemoresistance, miR-206

\footnotetext{
*Correspondence: linda202057@yahoo.com

${ }^{2}$ Department of Histology and Embryology, Dalian Medical University,

College of Basic Medicine Sciences, No 9 LvShun South Road-W, Dalian 116044, China

Full list of author information is available at the end of the article
}

\section{Introduction}

Ovarian cancer is one of the four most common malignant tumors and the most lethal gynecologic malignancy, with an associated annual mortality rate of 152,000 [1]. Epithelial ovarian cancer (EOC), which accounts for 
approximately $90 \%$ of ovarian cancer, has a poor prognosis due to late diagnosis and a high incidence of chemoresistance [2]. More than $70 \%$ of patients with ovarian cancer are diagnosed at an advanced stage (FIGO III and FIGO IV). The 5-year survival in such patients is less than $30 \%$ because of a lack of effective biomarkers for basic standard chemotherapy, prognosis, and personalized treatment [3]. Adjuvant chemotherapy drug resistance is a major cause of decreased overall survival in patients with advanced ovarian cancer. Platinumbased adjuvant chemotherapy is currently considered the standard of care for patients with advanced stage ovarian cancer following primary surgical cytoreduction, especially for serous ovarian cancer (OSC) [4]. Although most patients initially experience a clinical complete response (CR) to adjuvant chemotherapy, a minority (30-40\%) will have an incomplete response (IR) or progressive disease despite therapy [4]. Because of the lack of efficient biomarkers to predict chemoresistance, patients with such "platinum-resistant" tumors often receive multiple cycles of platinum-based chemotherapy without clinical benefit, lose the chance of the timely initiation of treatment with active agents, and often have a poor prognosis.

MicroRNAs (miRNAs) are a class of short, singlestranded, noncoding RNAs that are involved in the posttranscriptional regulation of genes through messenger RNA (mRNA) silencing [5]. A single miRNA targets and changes the expression of many genes. Using high-throughput technology, such as microarrays and quantitative RT-PCR for validation, many studies have found associations between miRNA expression levels and tumor type, biological behaviour, grade, response to treatment and prognosis [6]. These studies indicate the vital roles of miRNAs in neoplasia and the potential for miRNAs to serve as biomarkers of disease state and prognosis and predictors of drug resistance [7]. The mechanisms underlying platinum chemotherapy resistance are not fully understood, and no definite biomarkers that predict the response to platinum drugs have been found. The expression signatures of local or systemically circulating miRNAs that are underexpressed (tumor suppressors) or highly expressed (oncogenes) can serve as biomarkers for discriminating tumor origins or subtypes and directing chemotherapy $[7,8]$.

In the present study, by comparing the miRNA microarray profiles of cancer tissues from EOC patients who showed CR or IR to primary platinum-based chemotherapy, we found a subset of miRNAs that were differentially expressed in the CR and IR groups. Among these, miR-206 was one of the most significantly increased miRNAs in IR patients, and high miR-206 expression was strongly associated with poor patient prognosis. In vitro and in vivo studies confirmed that miR-206 was involved in the EOC response to cisplatin treatment. Our results suggested that miR-206 can be used as a biomarker to predict sensitivity to platinum-based chemotherapy and survival in ovarian cancer patients.

\section{Materials and methods \\ Patients and specimens}

Patients who were surgically treated for ovarian cancer between 2004 and 2010 at the Obstetrics and Gynecology Hospital of Dalian (Liaoning, China) were recruited into this study. All participants signed a consent form prior to the surgical procedure and the investigations. The present study was approved by the Institutional Review Board of the Ministry of Science and Technology of China, the Human Resource Management Office (Beijing, China) and the ethics committee of Dalian Medical University (Dalian, China). Clinicopathological data were collected, including subtype, age, FIGO stage, grade, status of lymphatic metastasis, survival and response to therapy. The therapeutic response was evaluated as previously reported [2]. In brief, according to the response to first-line platinum-based chemotherapy, the patients were classified into two groups. A complete response (CR) was defined as the complete disappearance of all measurable and assessable disease or, in the absence of measurable lesions, a normalization of the CA-125 $(<30$ $\mathrm{U} / \mathrm{mL}$ ) level following 3 cycles of adjuvant therapy. An incomplete response (IR) was classified as only a partial response, no response, or disease progression during primary therapy or any increase in the CA-125 level from baseline at study entry. The CA-125 response criteria were based on established guidelines $[9,10]$.

All patients underwent primary surgical cytoreduction followed by adjuvant treatment with platinum-based chemotherapy. The tumor specimens comprised primary ovarian cancer obtained from surgery prior to chemotherapy collected for the experiments. The slides for each case were evaluated by two expert pathologists. Only specimens containing $>70 \%$ tumor tissue were used for subsequent experiments. Seventeen EOC ovarian cancer tissues (formalin fixed paraffin embedded blocks) were collected for the miRNA array assay. Among these, 9 patients showed CR, and 8 showed IR after primary platinum-based therapy following surgery (Table 1). In the validation experiment, a separate cohort of patients was recruited from the Obstetrics and Gynecology Hospital of Dalian. Among these patients, 20 showed CR, and 19 showed IR after primary platinum-based therapy (Table 1).

\section{Cell culture}

The cisplatin-sensitive cell line OV2008 was derived from a patient with ovarian serous cystadenocarcinoma who 


\begin{tabular}{|c|c|c|c|c|}
\hline \multirow[t]{2}{*}{ Parameters } & \multicolumn{2}{|c|}{ Microarray } & \multicolumn{2}{|c|}{$\begin{array}{l}\text { Validation } \\
\text { cohort (qRT- } \\
\text { PCR) }\end{array}$} \\
\hline & CR & IR & CR & IR \\
\hline Number & 9 & 8 & 20 & 19 \\
\hline Age (Mean \pm SEM) & 49.4 & 48.7 & 51.3 & 50.46 \\
\hline \multicolumn{5}{|l|}{ FIGO stage } \\
\hline I & 1 & 1 & 1 & 1 \\
\hline$\|$ & & 2 & 2 & 1 \\
\hline III & 8 & 4 & 17 & 15 \\
\hline IV & & 1 & 0 & 2 \\
\hline \multicolumn{5}{|l|}{ Subtype } \\
\hline Low grade serous carcinoma & 1 & 1 & 1 & 3 \\
\hline High grade serous carcinoma & 8 & 5 & 19 & 16 \\
\hline Clear cell carcinoma & 0 & 1 & & \\
\hline Endometrioid carcinoma & 0 & 1 & & \\
\hline \multicolumn{5}{|l|}{ Mean serum CA125, m/ml } \\
\hline Before platinum & 952.1 & 1872.2 & 1023.1 & 1764.2 \\
\hline After platinum & 17.2 & 343.1 & 14.3 & 294.3 \\
\hline Mortality rate (\%) & & & $48.1 \%$ & $75 \%$ \\
\hline
\end{tabular}

$\mathrm{CR}$, Clinical complete responders; IR, Clinical incomplete responders

did not undergo prior chemotherapy, and its resistant variant, $\mathrm{C} 13$, originated from in vitro cisplatin challenges of OV2008 cells [11]. Another cisplatin-sensitive cell line, A2780, which was established from tumor tissue from an untreated patient and has been implicated as ovarian endometroid adenocarcinoma [12], and its corresponding cisplatin-resistant variant A2780/cis were also used. These cells were acquired as a gift from Professor Chun Peng (Department of Biology, York University, Toronto, Canada). These cell lines were maintained in RPMI-1640 (1x) medium supplemented with $10 \%$ fetal bovine serum (FBS) (Gibco, Thermo Fisher Scientific Inc., Waltham, MA, USA) and $1 \%$ PSA, sodium bicarbonate $(24 \mathrm{mM})$ and HEPES $(10 \mathrm{mM})$. All cell cultures were maintained at $37{ }^{\circ} \mathrm{C}$ in a humidified atmosphere with $5 \% \mathrm{CO}_{2}$.

\section{RNA extraction}

Total RNA was extracted from the FFPE EOC tissue samples using the Ambion mirVana microRNA Isolation Kit (Ambion Life Technologies, Austin, TX, USA). In brief, tissue deparaffinization was performed by gradient alcohol and xylene followed by protease digestion to remove the proteins covalently bound to RNA. The nucleic acid was isolated by an ethanol mixture and captured on a glass-fiber filter. The final nucleic acid was purified by high-ethanol washing and elution. The quantity and quality of the total RNA was verified with the Agilent RNA 6000 Nano Kit and the BioanalyzerTM (Agilent Technologies, Palo Alto, CA, USA).

\section{MiRNA microarray and data analysis}

The miRNA microarray was performed at the Shannon McCormack Advanced Molecular Diagnostics Laboratory Research Services, Dana Farber Cancer Institute, Harvard Clinic and Translational Science Center (Boston, MA, USA). A microarray platform optimized for the analysis of a panel of 768 human miRNAs (TaqMan ${ }^{\circledR}$ Array Human MicroRNA Card Set v2.0; Thermo Fisher Scientific Inc., Waltham, MA, USA) was used to analyze and compare the patterns of miRNA expression between $\mathrm{CR}$ and IR to platinum-based chemotherapy in EOC patients. Individual real-time quantitative polymerase chain reaction assays were formatted into a TaqMan lowdensity array (TLDA; Applied Biosystems). The normalized microarray data were managed and analyzed using StatMiner version 3.0 (Integromics ${ }^{\mathrm{TM}}$, Granada, Spain).

\section{Quantitative real-time PCR (qRT-PCR)}

The miR-206 expression pattern was determined by qRTPCR using a commercial TaqMan ${ }^{\mathrm{TM}}$ MicroRNA Reverse Transcription Kit specific to human miR-206 (Applied Biosystems, Thermo Fisher Scientific, USA). In brief, miR-206 was generated from 220 to $300 \mathrm{ng}$ of the total RNA in a single-step reaction by performing reverse transcription according to the manufacturer's instructions. PCR amplification was performed in a 96-well optical plate at $95{ }^{\circ} \mathrm{C}$ for $10 \mathrm{~min}$, followed by 40 cycles of $95{ }^{\circ} \mathrm{C}$ for $15 \mathrm{~s}$ and $60{ }^{\circ} \mathrm{C}$ for $60 \mathrm{~s}$, using U6 as a housekeeping gene control. The experiments were run in triplicate for each case to allow for technical variability. Real-time PCR was performed on an Agilent Technologies Stratagern MX3000P. The data were analyzed with Mxpro software.

\section{Stable transfection of miR-206 by plasmid}

The recombinant plasmid p-EGP-miR-206, which contained pre-miR-206 cloned into the pEGP-miR vector $(5.0 \mathrm{~kb})$, and its vector control pEGP-miR Null Control Vector were gifts from Dr Jin (Feinberg Cardiovascular and Renal Research Institute, Feinberg School of Medicine, Northwestern University, Chicago). The p-EGPmiR-206 plasmids were transformed into competent E. coli DH5 $\alpha$ cells (Takara Bio Inc. Dalian, China), and the bacterial strains were amplified in $1 \times$ LB supplemented with ampicillin. Then, plasmids were isolated by the E.Z.N.A. Endo-free Plasmid Mini Kit (Omega Bio-tek, Norcross, GA, USA). The p-EGP-miR-206 and pEGP-miR Null Control Vector plasmids were transfected into the A2780s and OV2008 cell lines by using Lipofectamine $^{\mathrm{TM}} 2000$ reagent (Thermo Scientific, 
Carlsbad, CA, USA) according to the manufacturer's instructions. Four days after transfection, the cells were selected by challenging the cells with the proper concentration of puromycin $(2 \mu \mathrm{g} / \mathrm{mL})$ to generate positive clones. Then, the puromycin-resistant clones were selected and cultured. At 4 weeks after cloning, we finally obtained cell lines with stable expression of pEGPmiR-206 (A2780s-206, OV2008-206) and pEGP-miR (A2780s-con, OV2008-con).

\section{MTS cell viability assay}

Cell survival was determined using the Cell Titer AQueous Non-Radioactive Cell Proliferation Assay Kit (Cat\# P9625; Promega Co., USA). In brief, cells were cultured in 96-well plates at a density of 1000 cells/well and then treated with $0,5,10,15,20,25,30,40,50$, and $60 \mu \mathrm{M}$ cisplatin for $48 \mathrm{~h}$ for A2780s cells or 0, 2.5, 5, 7.5, 10, 15, $20,30,40$, and $50 \mu \mathrm{M}$ cisplatin for $48 \mathrm{~h}$ for OV2008 cells. Twenty microliters of MTS/PMS solution composed of a novel tetrazolium compound [3-(4,5-dimethylthiazol2-yl)5-(3-carboxymethoxyphenyl)-2-(4-sulfophenyl)htetrazolium, inner salt; MTS] and an electron coupling reagent (phenazine methosulfate; PMS) at a ratio of 20:1 and $80 \mu \mathrm{L}$ of complete culture solution were added to one 96-well plate and incubated at $37^{\circ} \mathrm{C}$ in a humidified $5 \% \mathrm{CO}_{2}$ atmosphere for $3 \mathrm{~h}$. The absorbance at $490 \mathrm{~nm}$ was measured using an ELISA plate reader (PowerWavex 340, Bio-Tek Instruments Inc., Winooski, VT, USA). Each point represents the mean \pm S.D. of triplicates. Responses to drug treatment were assessed by standardizing the treatment groups to the untreated controls. The IC50 was calculated by the Bliss method.

\section{Cellular apoptosis assay with flow cytometry}

For the cellular apoptosis assay with flow cytometry, Annexin V/propidium iodide (PI) staining was performed using the Annexin V-FITC Apoptosis Detection Kit (KGA106; KeyGen Biotech, Nanjing, China). Ovarian cancer cells were initially seeded at a concentration of $5 \times 10^{5}$ cells $/ \mathrm{mL}$ in 6-well plates and incubated for $24 \mathrm{~h}$. OV2008 cells and C13 cells were then treated with $20 \mu \mathrm{M}$ cisplatin, and A2780CP and A2780s cells were treated with $15 \mu \mathrm{M}$ cisplatin. After exposure to the drugs for $48 \mathrm{~h}$, the cells were dissociated using $0.05 \%$ EDTA-free trypsin and washed with cold PBS. Approximately $1 \times 10^{6}$ cells were suspended in $100 \mu \mathrm{L}$ of Annexin V incubation reagent. After incubation in the dark for $20 \mathrm{~min}$ at room temperature, cellular fluorescence was analyzed by the BD FACSCalibur Flow Cytometer (BD Biosciences, USA) within $30 \mathrm{~min}$.

\section{Tumor cell wound healing assay}

After growth to $70 \%-80 \%$ confluence in 6 -cm cell culture dishes, the cells were incubated with cisplatin $(10 \mu \mathrm{M}$ for A2780s and $15 \mu \mathrm{M}$ for OV2008) for $12 \mathrm{~h}$, and then the cell monolayer was scratched across the center of the wells using a $10 \mu \mathrm{L}$ pipette, washed twice with MEM, and cultured in MEM without FBS for up to $48 \mathrm{~h}$. At the end of each experiment, images were captured using an Olympus IX73 microscope connected to an Olympus DP73 camera (Olympus corporation, Tokyo, Japan) at 0 , 8,16 , and $24 \mathrm{~h}$.

\section{Tumor cell invasion assay}

To analyze the invasion capacity, we first coated cell inserts $(8.0 \mu \mathrm{m}$ pore size membrane; Corning, Corning, NY, USA) with $100 \mu \mathrm{L}$ of Matrigel (at a dilution of 1:3 in DMEM) (BD Bioscience, San Jose, CA, USA). The cells were serum starved for $24 \mathrm{~h}$, and then $2 \times 10^{4}$ cells were seeded onto the cell inserts in the upper chamber in serum-free medium with $10 \mu \mathrm{M}$ or $20 \mu \mathrm{M}$ cisplatin. The bottom chamber, which contained 50\% DMEM with 10\% FBS and L-glutamine with $10 \mu \mathrm{M}$ or $20 \mu \mathrm{M}$ cisplatin, was used as a chemoattractant. After $24 \mathrm{~h}$, cells that invaded the lower surface of the filter were fixed with $4 \%$ paraformaldehyde, stained in $0.5 \%$ crystal violet, and counted using a microscope. Each experiment was performed in triplicate.

\section{Protein extraction and western blotting (WB)}

Total protein lysates were prepared using standard RIPA lysis buffer (Sigma-Aldrich) with proteinase and phosphatase inhibitors (Santa Cruz Biotechnology, Santa Cruz, CA, USA). The total protein content was estimated by the Pierce ${ }^{\mathrm{TM}}$ BCA Protein Assay Kit (Thermo Scientific) following the manufacturer's protocol. Protein lysates $(50 \mu \mathrm{g})$ were separated by $12 \%$ sodium dodecyl sulfate-polyacrylamide gel electrophoresis (SDS-PAGE) and transferred onto polyvinylidene fluoride (PVDF) membranes (Millipore, Billerica, MA, USA). The membranes were blocked in 5\% skim milk solution in TBST buffer for $1 \mathrm{~h}$ at approximately $24{ }^{\circ} \mathrm{C}$ and incubated with polyclonal Connexin 43 (1:500; Proteintech Group, Wuhan, China) and polyclonal GAPDH (1:2000; Proteintech Group, Wuhan, China) primary antibodies at $4{ }^{\circ} \mathrm{C}$ overnight. The membranes were incubated with horseradish peroxidase (HRP)-conjugated secondary antibody (1:5000, GE, HyClone) at $37^{\circ} \mathrm{C}$ for $2 \mathrm{~h}$ The protein bands were visualized with enhanced chemiluminescence (ECL; Advansta) and detected using a ChemiDocTM MP imaging system (Bio-Rad). The protein bands were then scanned using Image LabTM Software Version 4.1. 


\section{In vivo tumor xenograft study}

Twenty female SCID mice (approximately $20 \mathrm{mg}$ ) were purchased from the Experimental Animal Center of Dalian Medical University. The research protocol was approved, and the mice were maintained in accordance with the institutional guidelines of the Committee on the Use and Care on Animals (Dalian Medical University, Dalian, China). Ovarian cancer cell lines stably transfected with p-EGP-miR-206 (A2780s-206, OV2008-206) and vector control (A2780s-con, OV2008-con) plasmids were injected $\left(5 \times 10^{6}\right.$ cells per mouse in $\left.200 \mu \mathrm{L}\right)$ subcutaneously into the left axilla or back of 20 female SCID mice. The tumors were allowed to grow to approximately $100 \mathrm{~mm}^{3}$ for A2780s and $30 \mathrm{~mm}^{3}$ for OV2008, and then the mice were given $4 \mathrm{mg} / \mathrm{kg}$ cisplatin through intraperitoneal injection once every 3 days. Tumor volume in SCID mice was measured every two days before and after cisplatin treatment. The animals in the A2780s group were sacrificed at 21 days after tumor implantation, and the animals in the OV2008 group were sacrificed at 28 days after tumor implantation to confirm the presence of tumors and weigh the established tumors.

\section{Statistical analysis}

The Mann-Whitney U test was performed for qRT-PCR statistical analysis. The data are expressed as the arithmetic mean \pm SD of the number (n) of experiments. The samples were analyzed with repeated measures analysis of variance, and differences in incidences were analyzed using one-way ANOVA or t test via SPSS software and GraphPad Prism 8. Overall survival was defined as the time from initial cytoreductive surgery to the date of the last follow-up or death. Survival time courses were evaluated using the Kaplan-Meier method, and the groups were compared using the log rank test. Receiver operating characteristic (ROC) curve analysis was performed for selected miRNAs. In addition, the area under the curve (AUC) values and 95\% confidence intervals (CIs) were calculated to evaluate the specificity and sensitivity for predicting chemosensitivity to cisplatin. $\mathrm{P}<0.05$ was considered significant.

\section{Results}

miR-206 was significantly increased in EOC with IR, and high miR-206 correlated with poor prognosis in EOC patients

To identify the unique miRNA expression pattern associated with resistance to platinum-based chemotherapy in EOC patients, we applied miRNA microarray technology to EOC specimens from CR and IR patients. Of the 768 miRNAs analyzed by microarray, 39 miRNAs showed at least a twofold difference $(\mathrm{P}<0.05)$ between $\mathrm{CR}$ and IR patients. Thirty-four miRNAs were downregulated and 5 were upregulated in the IR specimens [2]. Among these differentially expressed miRNAs, miR-206 was one of the most upregulated miRNAs in the IR group compared with the CR group (expression ratio of IR group to $\mathrm{CR}$ group $=10.13, \mathrm{P}=1.59 \mathrm{E}-06$, adjusted $\mathrm{P}=1.07 \mathrm{E}-03$ ) (Fig. 1a).

Then, the microarray results were validated by qRTPCR with another 39 fixed specimens from EOC patients with complete clinicopathological data and survival information. These specimens contained 19 IR EOC cases and 20 CR EOC cases (Table 1). Consistent with the microarray results, miR-206 was significantly upregulated in the IR EOC samples compared with the CR EOC samples (Fig. 1b) $(\mathrm{P}=0.0003)$. To explore the diagnostic potential of miR-206 for chemoresponsiveness, ROC curves were constructed (Fig. 1c). The area under the ROC curve (AUC) for miR-206 was 0.811 (95\% CI $0.677-0.93344, \mathrm{P}=0.007$ ), showing relatively high accuracy in chemoresponsiveness prediction. The patient response to platinum-based therapy was accurately predicted in 31 of 39 patients for an overall accuracy of 79.48\% (Fig. 1b). A Mann-Whitney U test for statistical significance $(\mathrm{P}<0.001)$ confirmed that this predictor distinguished IR patients from CR patients.

The correlations between miR-206 expression and other clinicopathological features, including age $(>50$ or $\leq 50$ years), lymph node metastasis, grade and FIGO stage, were analyzed. miR-206 expression was first separated into high and low expression defined by reference to the median value of the miRNA in the tumor samples. Chi-square tests showed that the expression of miR-206 was not associated with these features except chemosensitivity (Table 2).

To further investigate the role of miR-206 in clinical progression, the patients were followed up, and the clinicopathological data were used in the survival analysis. Kaplan-Meier survival analysis revealed that high miR-206 expression was associated with shorter overall survival (Fig. 1d, Table 3). In addition to miR-206, FIGO staging and sensitivity to chemotherapy (Fig. 1e) were also shown to be associated with survival (Table 3). This result supports the hypothesis that miR-206 may play an important biological role in mediating survival in cancers by modulating the response to chemotherapy. miR-206 may serve as an effective predictor of platinum chemosensitivity and survival in patients with EOC.

The somatic mutations and prognostic significance of miR-206 were further investigated in some current widely used databases. The genetic alterations identified by The Cancer Genome Atlas (TCGA) as affecting miR206 in OSC are shown in Fig. 2a and b, which indicate a $3 \%$ amplification of the gene in a 201 OSC patient cohort (TCGA, PanCancer Atlas) and 1.5\% amplification of the 


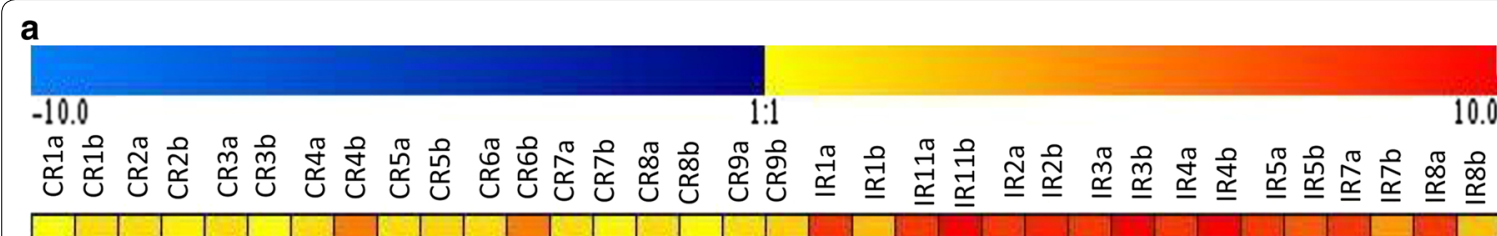

his-miR-206

b

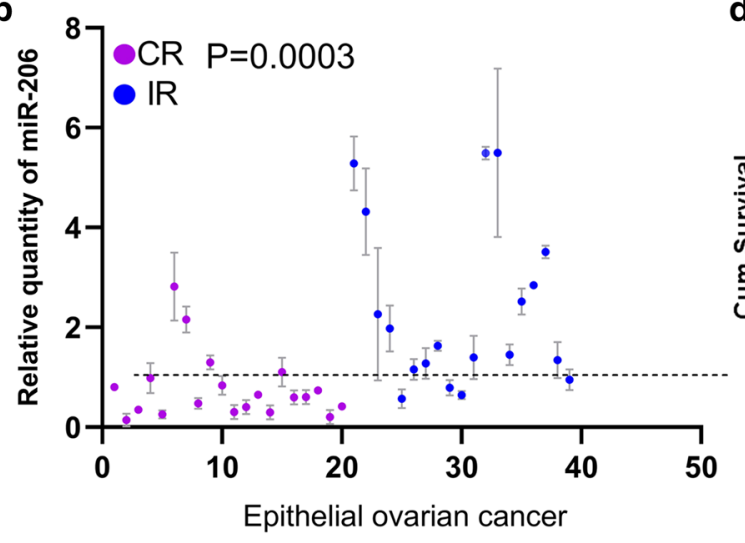

d

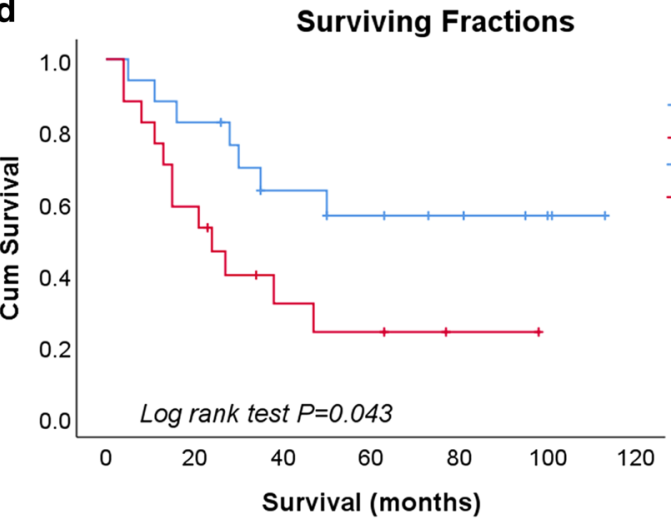

miR-206

$\neg$ Low

$\neg$ High

+Low-censored

+ High-censored

C

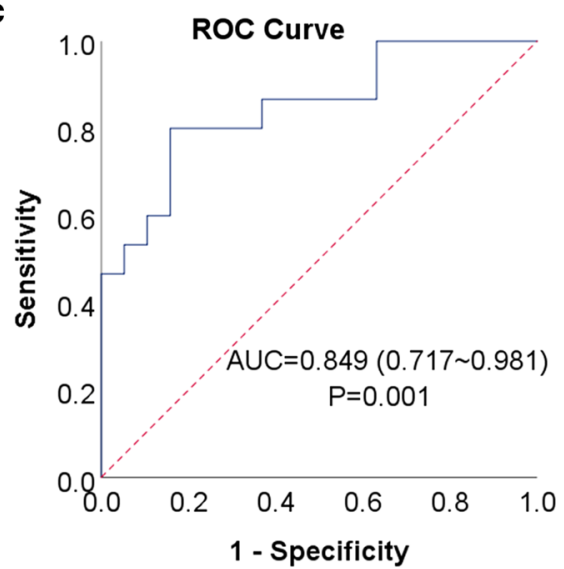

e

Surviving Fractions

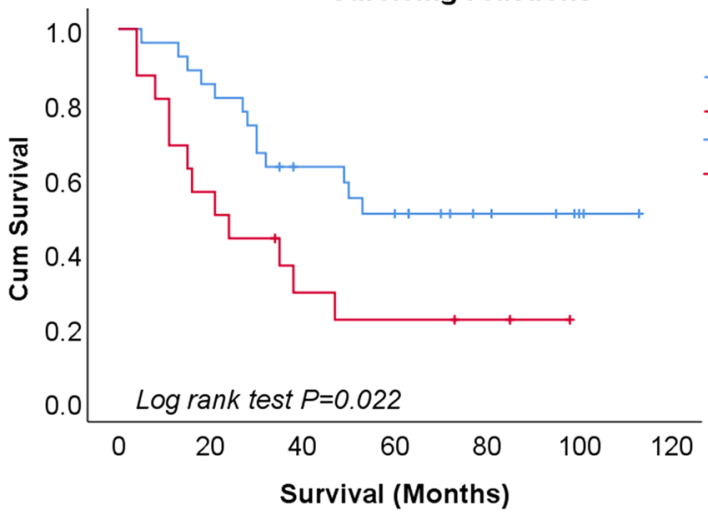

Fig. 1 miR-206 levels predict the response to platinum-based chemotherapy and survival in Chinese EOC patients. a Hierarchical clustering of miRNA microarray analysis between epithelial ovarian cancer (EOC) samples with complete response (CR) and incomplete response (IR) to platinum-based chemotherapy $(n=17)(P<0.0001)$. $\mathbf{b}$ miR-206 expression in a verified cohort of EOC patients ( $n=39)$ by qRT-PCR. miR-206 was significantly upregulated in the IR group $(n=19)$ vs. the CR group $(n=20)(P=0.0033)$. c Receiver operating characteristic (ROC) curve of the cisplatin responders. A Mann-Whitney $U$ test demonstrated that miR-206 expression distinguished IR patients from $C R$ patients ( $<<0.001)$. The area under the curve (AUC) is 0.829 (0.707-0.951). $\mathbf{d}$ Kaplan-Meier curves showing the overall survival of EOC patients stratified by expression levels of miR-206. The qRT-PCR data of miR-206 was separated into high and low expression groups by the median value. ( $n=20$ for $C R$ and $n=19$ for $I R$, $\mathrm{P}<0.001)$. e Kaplan-Meier curves showing that the response to chemotherapy was related to patient prognosis

gene in a 316 OSC patient cohort (TCGA, Nature 2011). No other genetic alterations, such as deletions or mutations, were detected. Survival analysis by KmPlot [13] showed that in ovarian cancer, patients with low miR-206 expression appeared to have a longer median survival time (49.43) than those with high miR-206 expression (44.53); however, the difference was not significant $(\mathrm{P}=0.068)$ (Fig. 2c). We then analyzed the prognostic significance of miR-206 in EOC patients with different races, grades, and mutation burdens (Additional file 1: Fig. S1) and found that miR-206 expression was significantly associated with poor prognosis in high-grade (grade 3) EOCs $(\mathrm{P}=0.036)$ (Fig. 2d).

\section{Overexpression of miR-206 increased the chemotherapy resistance of EOC to cisplatin}

To further verify the relationship between miR-206 expression and responsiveness to platinum-based 
Table 2 Correlation between the miR-206 expression and clinicopathologic parameters of patients with epithelium ovarian cancer

\begin{tabular}{lrrrr}
\hline $\begin{array}{l}\text { Clinicopathologic } \\
\text { parameters }\end{array}$ & N & \multicolumn{2}{c}{ miR-206 expression } & P \\
& & Low & High & \\
\hline Age in years & & & & 0.253 \\
$\quad<50$ & 18 & 10 & 8 & \\
$\geq 50$ & 21 & 10 & 11 & \\
Subtypes & & & & \\
LGSC & 4 & 2 & 2 & 0.229 \\
HGSC & 35 & 18 & 17 & \\
FIGO stage & & & & 0.183 \\
I & 2 & 0 & 2 & \\
II & 3 & 2 & 1 & \\
III & 32 & 18 & 14 & \\
IV & 2 & 0 & 2 & \\
LN metastasis & & & & \\
Absent & 13 & 7 & 6 & \\
Present & 26 & 14 & 12 & \\
Chemotherapy & & & & \\
CR & 20 & 16 & 4 & 0.001 \\
IR & 19 & 4 & 15 & \\
\hline N & & & & \\
\hline
\end{tabular}

$\mathrm{N}$, number; $\mathrm{FIGO}$ stage, International Federation of Gynecology and Obstetrics stage; P, P-value; LGSC, low grade serous carcinoma; HGSC, high grade serous carcinoma; $\mathrm{CR}$, complete response; $\mathrm{IR}$, incomplete response

The Ps set in italic considered statistically significant at $<0.05$ chemotherapy in ovarian cancer, two pairs of parental EOC cell lines, A2780s and OV2008, known as cisplatin-sensitive, and their cisplatin-resistant variants A2780CP and $\mathrm{C} 13$ were used for in vitro experiments. The qRT-PCR results showed significantly higher miR206 expression levels in $\mathrm{C} 13$ and A2780CP cells than in their cisplatin-sensitive counterparts. These results are consistent with those of the clinical EOC patient specimens (Fig. 3a).

To further investigate whether miR-206 is functionally involved in cellular sensitivity to cisplatin, the expression vector pEGP-miR (5.0 kb) carrying pre-miR-206 was transfected into two cisplatin-sensitive cell lines, OV2008 and A2780s, which have low miR-206 expression. After two weeks of antibiotic selection, miR-206 was confirmed to be overexpressed in the stably transfected cell lines (OV2008-206 and A2780s-206). miR-206 expression was hundreds-fold higher in OV2008-206 and A2780s-206 cells than in empty vector-transfected controls (A2780scon and OV2008-con) (Fig. 3b).

We then investigated the effects of miR-206 overexpression on sensitivity to cisplatin chemotherapy in sensitive cell lines. The cells were treated with different concentrations of cisplatin. The MTS results showed that A2780s-206 and OV2008-206 cells were more resistant to cisplatin than the controls (A2780s-con, OV2008con) (Fig. 3c). The drug concentrations that inhibited cell growth by $50 \%$ (IC50 values) in the A2780s-206

Table 3 Univariate analysis of overall survival in patients with epithelial ovarian cancer

\begin{tabular}{|c|c|c|c|c|c|c|}
\hline & \multirow[t]{2}{*}{ Number } & \multirow[t]{2}{*}{ Estimate } & \multirow[t]{2}{*}{ Std. error } & \multicolumn{2}{|c|}{$95 \%$ Confidence interval } & \multirow{2}{*}{$\begin{array}{l}\text { P (Log Rank, } \\
\text { Mantel-Cox) }\end{array}$} \\
\hline & & & & Lower bound & Upper bound & \\
\hline Age & & & & & & 0.572 \\
\hline$\leq 50$ & 17 & 64.900 & 10.051 & 45.200 & 84.600 & \\
\hline$>50$ & 22 & 52.803 & 8.234 & 36.665 & 68.941 & \\
\hline Chemotherapy sensitivity & & & & & & 0.022 \\
\hline$C R$ & 20 & 71.410 & 8.417 & 54.913 & 87.907 & \\
\hline $\mathbb{I R}$ & 19 & 37.313 & 8.808 & 20.048 & 54.577 & \\
\hline miR-206 expression & & & & & & 0.043 \\
\hline Low & 20 & 74.923 & 11.042 & 53.280 & 96.566 & \\
\hline High & 19 & 38.825 & 8.969 & 21.246 & 56.404 & \\
\hline Subtype & & & & & & 0.245 \\
\hline LGSC & 4 & 74.666 & 10.091 & 59.289 & 93.044 & \\
\hline HGSC & 35 & 62.623 & 8.678 & 45.613 & 79.632 & \\
\hline FIGO stage & & & & & & 0.016 \\
\hline I & 2 & & & & & \\
\hline$\|$ & 3 & 75.500 & 3.889 & 67.877 & 83.123 & \\
\hline III & 32 & 56.921 & 7.655 & 41.917 & 71.925 & \\
\hline IV & 2 & 12.500 & 8.500 & 0.000 & 29.160 & \\
\hline
\end{tabular}

FIGO stage, International Federation of Gynecology and Obstetrics stage; HGSC, high grade serous carcinoma; LGSC, low grade serous carcinoma; CR, complete response; IR, incomplete response; $\mathrm{P}$, $\mathrm{P}$-value

The Ps set in italics considered statistically significant at $<0.05$ 

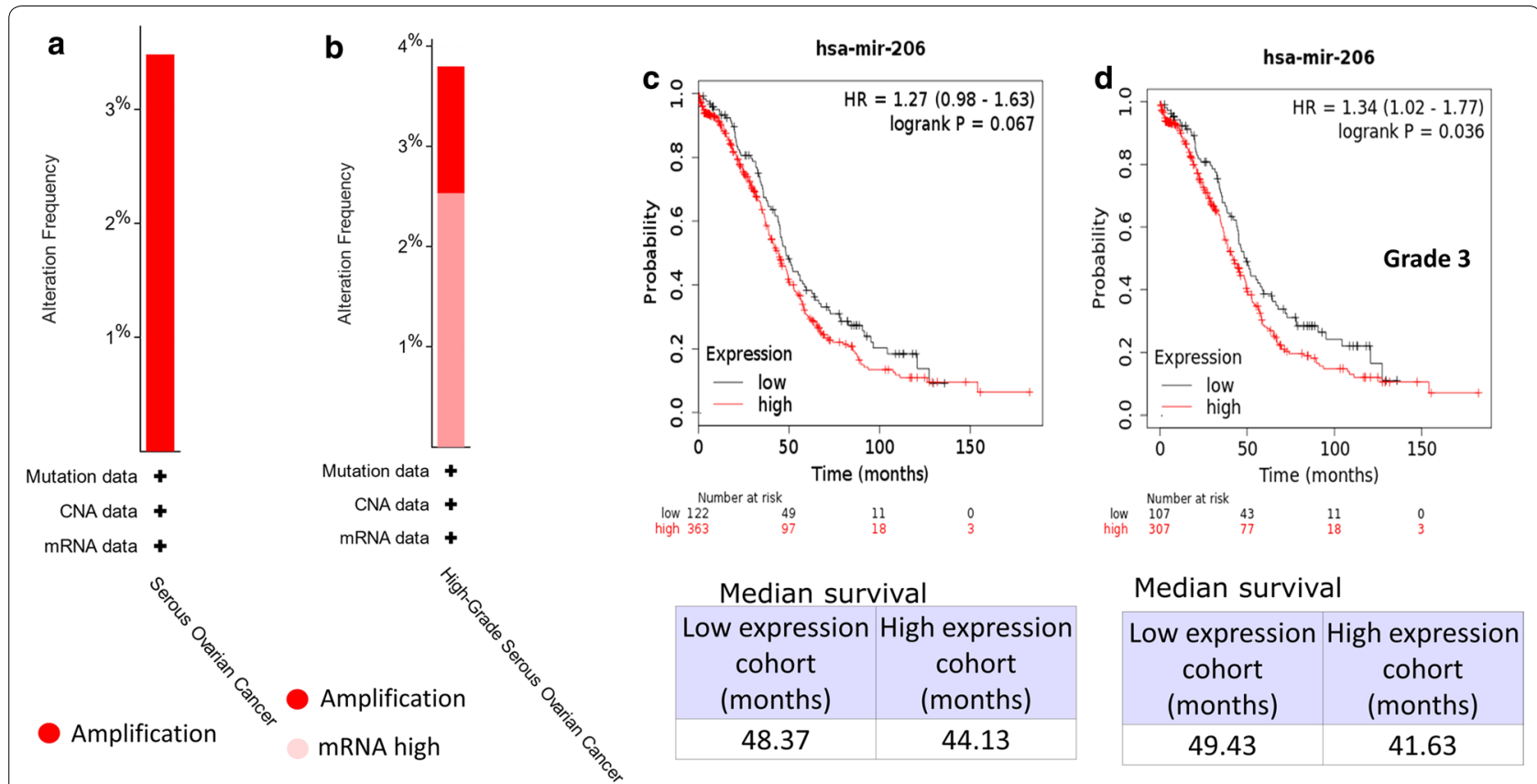

Fig. 2 Genetic alterations and survival analysis of miR-206 in ovarian cancer. $\mathbf{a}, \mathbf{b}$ Graphs indicate the frequency of miR-206 somatic mutations in ovarian cancers extracted from cancer studies in TCGA (TCGA, PanCancer Atlas (a) and TCGA, Nature 2011 (b)). c, d Kaplan-Meier diagrams showing the overall survival of patients with ovarian cancer (c) and grade 3 ovarian cancer (d) depending on the expression of miR-206 in kmplot.com

cells and OV2008-206 cells were $\sim 1.5$-fold and 2.5-fold higher, respectively, than those in their controls $(\mathrm{P}<0.01)$ (Fig. 3d). These data indicated that forced miR-206 expression promoted cisplatin resistance in EOC cell lines.

Cisplatin (DDP) and other platinum-based cancer drugs bind to double-stranded DNA and form DNA adducts, interfering with DNA replication and RNA transcription and ultimately triggering apoptosis. We then examined the effect of miR-206 overexpression on cisplatin-induced cell cycle changes and apoptosis. After the cells were treated with cisplatin for $24 \mathrm{~h}$, flow cytometric data indicated that miR-206 overexpression promoted cell cycle progression and decreased apoptosis during cisplatin treatment. Compared with that in the negative control, the cell cycle G2 phase ratio was decreased, and the G1 and S phase ratio was increased in A2780s-206 cells (Fig. 3e, f). The proportion of A2780s-206 and OV2008-206 cells in early apoptosis was significantly lower than that of the negative controls (Fig. 3g, h). These data indicated that miR-206 overexpression significantly decreased the cytotoxicity caused by cisplatin in A2780s and OV2008 cells.
miR-206 abrogated the suppressive effect of cisplatin on migration and invasion in cisplatin-sensitive ovarian carcinoma cells

The progression of a malignant tumor is determined by the metastatic and invasive properties of tumor cells, which allow malignant cells to invade the extracellular matrix and metastasize to distant sites. We investigated the effect of miR-206 on the migration and invasion ability of EOC cells, especially during primary chemotherapy.

The wound healing assay showed that the speed of migration of both OV2008-206 and A2780s-206 cells was significantly faster than that of the corresponding control cells A2780s-con $(\mathrm{P}<0.001)$ and OV2008-con $(\mathrm{P}<0.001)$, which suggested that miR-206 promotes migration in these EOC cells (Fig. 4a-c). When the cells were treated with cisplatin, consistent with their cisplatin-sensitive nature, the migration of the two cell lines A2780-con and OV2008-con was significantly decreased $(\mathrm{P}=0.034, \mathrm{P}=0.0025)$. However, for the cells with stably enforced miR-206 expression (OV2008-206+DDP and A2780s-206 + DDP), there was no significant change in the migration index compared with the corresponding untreated cell lines OV2008-206 and A2780s-206 $(\mathrm{P}>0.05)$ (Fig. 4a-c).

Invasion ability was tested using quantitative Boyden chamber analysis. Similar to the results of the wound healing assay, miR-206 significantly promoted the 

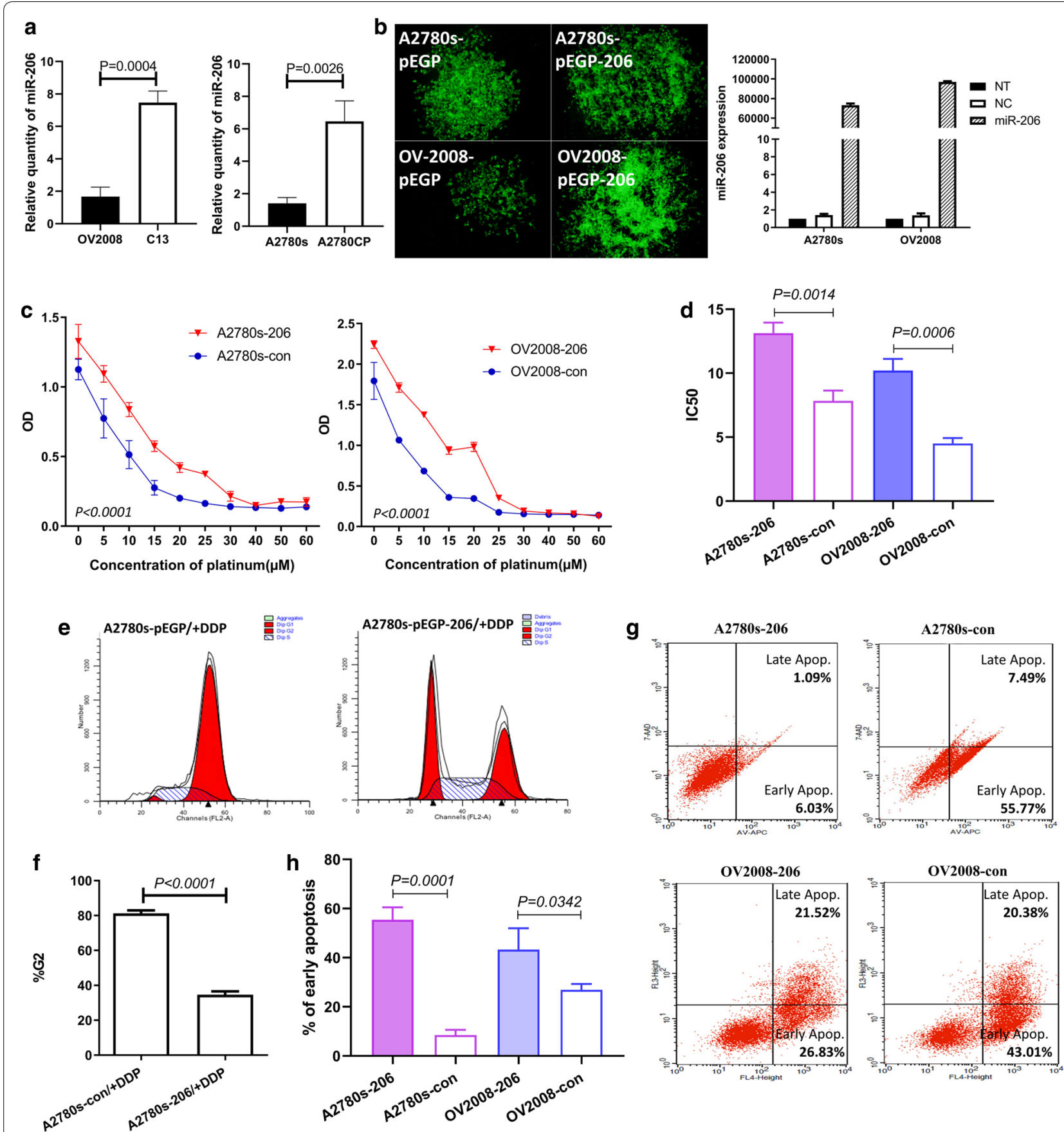

Fig. 3 Overexpression of miR-206 increased the resistance of EOC to cisplatin. A2780s and OV2008 cells were stably transfected with pre-miR-206 or vector control and then subjected to different assays. a qRT-PCR showed miR-206 expression in parental cisplatin-sensitive EOC cell lines A2780s and OV2008 and their cisplatin-resistant variants A2780CP and C13. b qRT-PCR showed miR-206 expression in various EOC cell lines. cThe MTS results show the dose-response curve of cisplatin. $\mathbf{d}$ The IC50 values are shown. e Flow cytometry results showed the comparison of the cell populations in the G0/G1, S and G2/M phases between the A2780s and A2780s-206 groups. $f$ Bar graphs showing the percentage of cells in the G2 phase detected by flow cytometry. $\mathbf{g}$ Annexin $\mathrm{V}$ flow cytometry assessment of the apoptotic cell population after $24 \mathrm{~h}$ of cisplatin treatment. $\mathbf{h}$ The percentage of cells in early apoptosis

invasion of EOC cells, as shown by the finding that the number of transferred cells in the OV2008-206 and A2780s-206 cell lines was greater than that in the OV2008-con $(\mathrm{P}<0.0001)$ and $\mathrm{A} 2780$ s-con $(\mathrm{P}=0.021)$ 


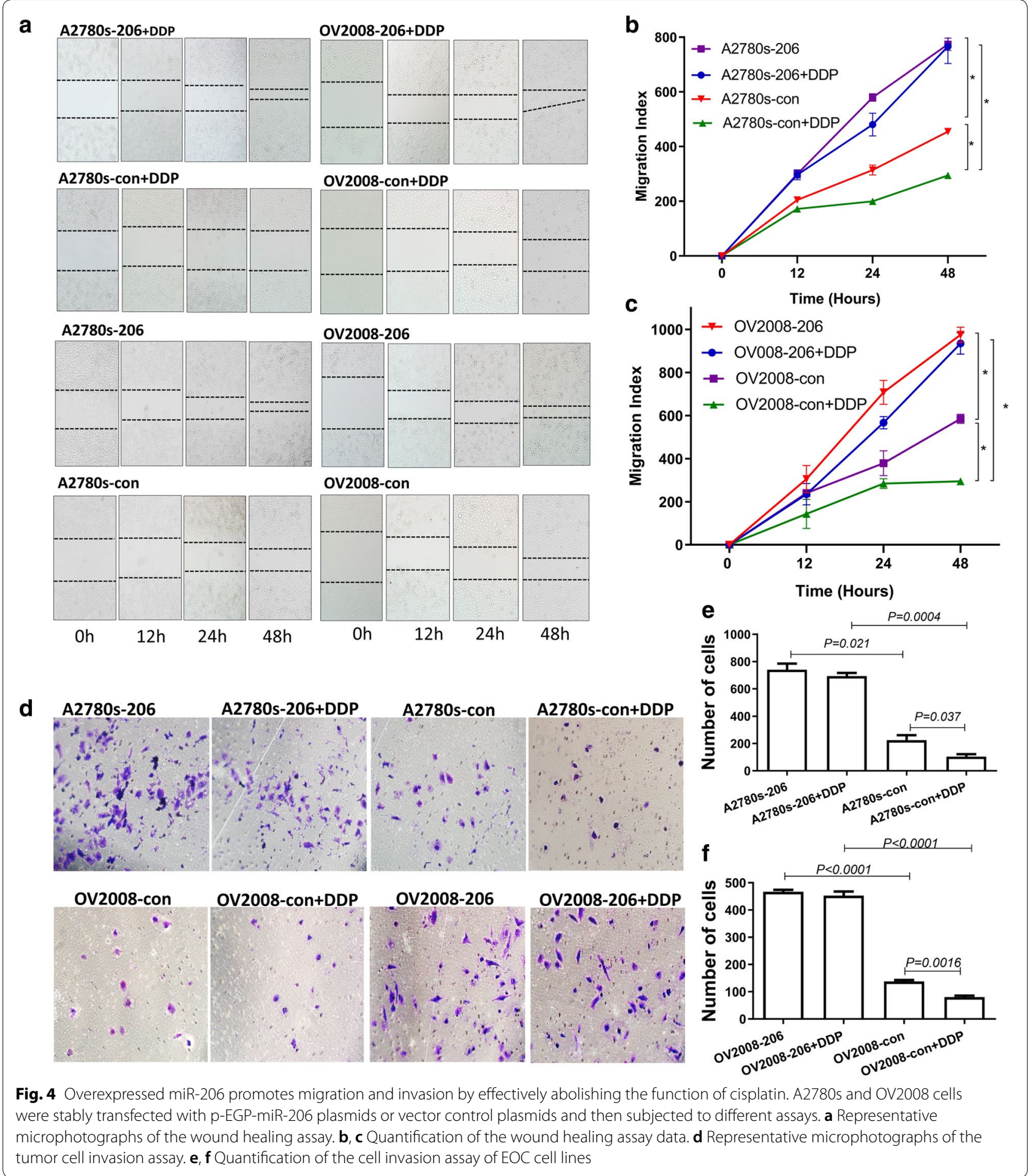

cells (Fig. 4d-f). When the cells were treated with cisplatin, the invasion ability was clearly inhibited in the cisplatin-sensitive cell lines OV2008-con and A2780s-con $(\mathrm{P}<0.05)$, while for cells with high miR-206 expression
(A2780s-206 and OV2008-206), cisplatin treatment did not affect the number of cells transferred to the other side of the chamber $(\mathrm{P}>0.05)$ (Fig. $4 \mathrm{~d}-\mathrm{f})$. These data indicated 
that miR-206 abrogated cisplatin-reduced migration and invasion and reduced the cytocidal effect of cisplatin.

\section{miR-206 promoted cisplatin chemoresistance by directly targeting Connexin 43 (Cx43)}

Cx43 has been found to be a direct target of miR-206 in many cells, including smooth muscle cells [14], myocardial cells [15], type II alveolar epithelial cells [15] and breast cancer cells [16]. Cx43 is a gap junction protein that promotes cisplatin cytotoxicity [17]. To investigate whether miR-206 promotes cisplatin chemoresistance by targeting $\mathrm{Cx} 43$ in EOC, we examined the effect of miR-206 on the expression of Cx43 in EOC cell lines. Western blot analysis showed that miR-206 overexpression significantly reduced the expression of $\mathrm{Cx} 43$ in the A2780s and OV2008 cell lines (Fig. 5a). Then, we examined the relationship between $\mathrm{Cx} 43$ expression and platinum chemosensitivity in ovarian cancer cell lines. The expression of $\mathrm{Cx} 43$ in two platinum-sensitive EOC
miR-206 promoted cisplatin chemoresistance in EOC in vivo

To explore the role of miR-206 in cisplatin resistance in vivo, we used a subcutaneous injection model in immune-deficient nude mice. A2780s-206 and OV2008206 cells and their corresponding controls were injected subcutaneously into nude mice, and the tumors were allowed to grow for approximately 2 weeks. When the implanted tumors reached a certain size, the mice were treated with cisplatin at $4 \mathrm{mg} / \mathrm{kg}$ via intraperitoneal injection 2 times per week for 1 to 2 weeks (Fig. 6a). The tumor growth rate was recorded.

Tumors derived from A2780s-206 cells developed much earlier and grew faster than those in the control group (Fig. 6a, b). After cisplatin treatment, the A2780s-con tumors ceased growing, some tumors began to shrink, and the tumors were confined to the site of implantation, while the A2780s-206 tumors continued growing and diffused to different parts of the body

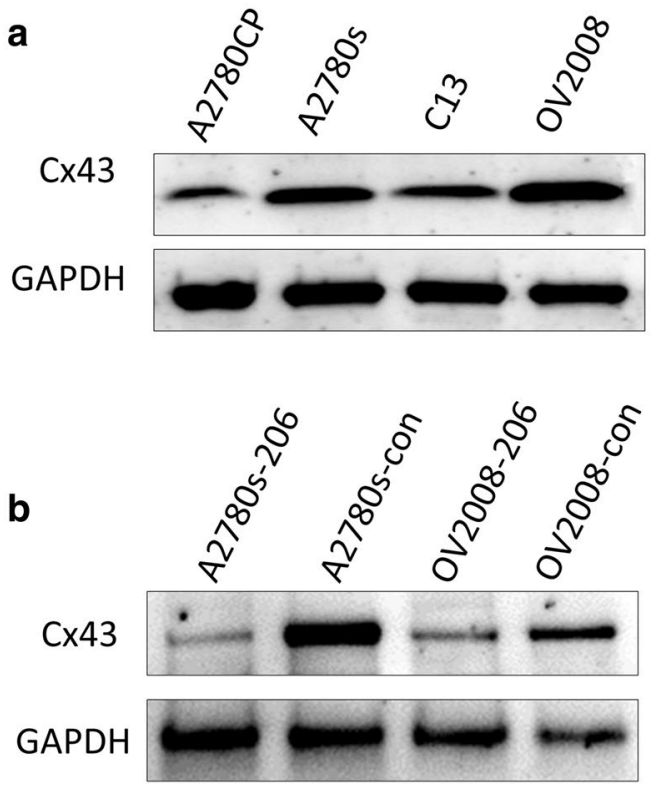

c ODOD (201667 at)

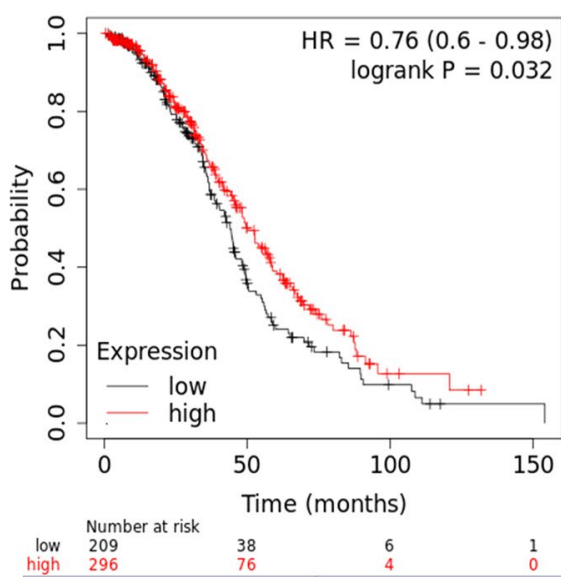

Low expression High expression cohort (months) cohort (months)

44.03

50.3

Fig. 5 miR-206 targets Cx43. a Western-blot detection of the expression of Cx43 protein in ovarian cancer cell lines. b Western-blot detection of the expression of $\mathrm{Cx} 43$ protein after up-regulation of miR-206. c Kaplan-Meier diagrams showing the overall survival of EOC patients who received platinum chemotherapy depending on the expression of Cx43 mRNA in kmplot.com

cell lines, A2780s and OV2008, was significantly higher than that in their cisplatin-resistant variants, A2780CP and $\mathrm{C} 13$ (Fig. 5b), which is the opposite of the expression of miR-206 in these cells. Survival analysis of data from TCGA by KmPlot showed that high Cx43 miRNA expression was associated with better overall survival in patients who received platinum chemotherapy $(\mathrm{P}=0.032)$ (Fig. 5c).
(Fig. 6a, c). Cachexia in mice from advanced carcinoma was clearly observed in A2780s-206 nude mice after 2-3 treatments, and the cachexia symptoms developed even earlier and to a greater degree in A2780s-206 mice injected with cisplatin.

The same experiment was performed using OV2008 cells. Before chemotherapy, although the size of OV2008206 tumors grew slightly larger than that of OV2008-con tumors, there was no significant difference in tumor size 
(See figure on next page.)

Fig. 6 miR-206 enhances EOC chemoresistance to cisplatin in vivo. Xenograft tumor growth derived from subcutaneously injected EOC cells stably transfected with p-EGP-miR-206 plasmids (A2780s-206 and OV2008-206) or vector control plasmids (A2780s-con and OV2008-con) in 20 female SCID mice. Tumors were allowed to grow to approximately $100 \mathrm{~mm} 3$ for A2780s and $50 \mathrm{~mm} 3$ for OV2008, and then the mice were given $4 \mathrm{mg} /$ $\mathrm{kg}$ cisplatin through intraperitoneal injection once every 3 days. a Tumors developed in the four groups of mice before the dissection of tumors. $\mathbf{b}$ Tumor volume in SCID mice was measured every two days before cisplatin treatment (some tumors are indicated by arrows). c Tumor volume in SCID mice was measured every two days after cisplatin treatment. $\mathbf{d}$ Tumor weight of SCID mice at the termination of the experiments. e qRT-PCR showed miR-206 expression in implanted tumors derived from EOCs stably transfected with miR-206 and empty vector

between the two groups (Fig. 6a, b). After cisplatin treatment, consistent with the results of A2780s, cisplatin profoundly diminished the volume of the implanted tumors derived from OV2008-con cells, while it exerted no observable effect on the implanted tumors derived from OV2008-206 cells (Fig. 6a, c). These results demonstrated that upregulation of miR-206 significantly promoted the chemoresistance of EOC to cisplatin treatment.

After chemotherapy, samples were collected, and the tumor sizes and weights were measured. The results showed that the volume of tumors derived from miR206-upregulated cell lines (A2780s-206, OV2008-206) was significantly larger $(\mathrm{P}<0.001)$ than that of tumors derived from the controls (A2780s-con, OV2008-con) (Fig. 6d). miR-206 expression in the tumors was verified by qRT-PCR. The results showed that miR-206 expression in tumor tissue derived from A2780s-206 and OV2008-206 cell lines was $20.99 \pm 2.41$ and $17.64 \pm 4.67$ times higher than that in tumors derived from the vector control cells (Fig. 6e). These results strongly suggested that miR-206 enhanced resistance to cisplatin chemotherapy in EOC.

\section{Discussion}

The platinum-taxane doublet represents the gold standard treatment in EOC [18]. However, not all EOCs respond well to platinum-based regimens. The initial response rates are $60-80 \%$; eventually, however, the majority of patients become platinum-resistant and experience subsequent relapse. More than $20 \%$ of ovarian cancer patients with platinum-resistant tumors do not benefit from first-line platinum-based chemotherapy. The identification of reliable biomarkers enabling clinicians to distinguish IR from CR subjects before chemotherapy is one of the main goals of translational medicine.

In recent years, enormous efforts have been made to identify effective biomarkers that can predict sensitivity to platinum-based chemotherapy in EOC. A subset of miRNAs has been found [2, 19-25], and only a few miRNAs overlap (Additional file 2: Table S1). Further validation is still needed. By microarray, we identified a spectrum of miRNAs that significantly differentiated IR samples from CR samples [2]. Among these miRNAs, our group validated several of the most significant miRNAs, including miR-770-5P [2], miR-136 [10], miR-224-5p [18] and miR-206, by functional studies and qRT-PCR in additional patient cohorts. We believe that a single miRNA or a combination of these miRNAs may be used as a biomarker to predict chemosensitivity to platinum drugs.

Among the dysregulated miRNAs, miR-206 was one of the most significantly upregulated miRNAs in EOC samples from IR patients compared with those from CR patients. This result was further confirmed in a validation cohort including 39 cases of EOC and two pairs of corresponding EOC cell lines. Retrospective assessments of miR-206 as a predictor of primary chemosensitivity showed that high miR-206 expression predicted chemoresistance with an accuracy of up to $79.48 \%$. These findings suggested that miR-206 expression levels can be used as a possible biomarker for the therapeutic response to platinum-based chemotherapy in EOC and may be used as a biomarker to assist in selecting the appropriate chemotherapy regimen before treatment begins, helping to avoid unnecessary toxicities and enhance quality of life. Moreover, our results also showed that high miR-206 expression correlated with unfavorable survival outcomes in EOC patients. Using data from KmPlot, we found that high miR-206 expression was related to poor overall survival in high-grade EOCs. These data suggested that miR-206 may also be a valuable prognostic predictor, especially for high-grade EOCs.

To further investigate the functional effect of miR-206 on platinum-based chemotherapy, we stably enforced miR-206 expression in platinum-sensitive EOC cell lines. In vitro experiments showed that overexpression of miR-206 in cisplatin-sensitive EOC cell lines significantly increased cell viability, migration and invasion in the presence of cisplatin and decreased cisplatininduced apoptosis. In vivo animal experiments showed that miR-206 promoted the growth of tumors derived from A2780s-206 cells but not OV2008-206 cells. The miR-206-upregulated tumors derived from both cell lines were more resistant to cisplatin treatment. The in vivo study suggested that miR-206 may not promote proliferation in EOC cell lines, but it definitely enhanced the chemoresistance of the cells to cisplatin. The results of both in vitro and in vivo experiments indicated that 


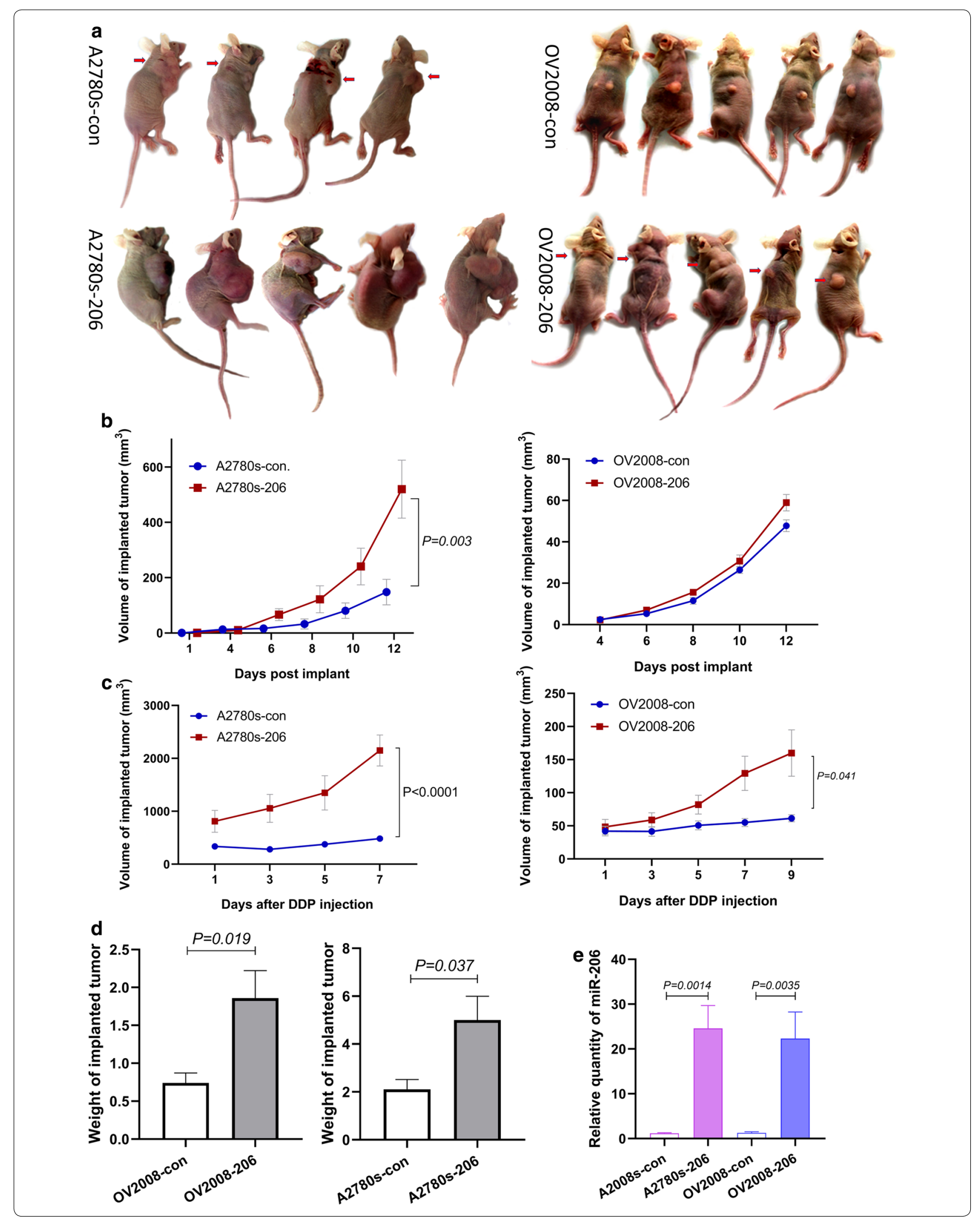


miR-206 plays an important role in enhancing chemoresistance to cisplatin.

miR-206 belongs to the miR-206/miR-133b cluster located in chromosomal region $6 \mathrm{p} 12.2$. This cluster is considered myomiRs [26]. miR-206 acts to promote myogenic differentiation [27] and plays a positive role in the regeneration of muscles during injury. The role of miR-206 in cancers is complicated and controversial. Decreased expression of miR-206 was found in rhabdomyosarcoma [26], lung cancer [28], ER + breast cancer $[29,30]$, renal cell carcinoma [31], ER alpha + endometrioid adenocarcinoma [32], hepatocellular carcinoma [33, 34] and glioma [35]. Upregulation of miR-206 inhibits the migration, invasion and proliferation of breast cancer [30], renal cell carcinoma [31], glioma [35], and head and neck squamous cell carcinoma [31], suggesting a tumor suppressor role of miR-206. Increased expression of miR206 was found in breast cancer [30,36], esophageal carcinoma [37] and some soft tissue sarcomas [38], and high miR-206 expression was related to the poor prognosis of breast cancer [36] and esophageal carcinoma patients [37]. Upregulation of miR-206 in breast cancer cells promoted the migration, invasion and proliferation of breast cancer cells [30]. These data indicated that miR-206 can also serve as an oncomiR. It appears that the role of miR206 in cancers is tissue specific.

The mechanism of miR-206 in platinum resistance remains unclear. Commonly, miRNAs exert effects through their target protein molecules. Many proteins have been reported to be directly targeted by miR-206, including estrogen receptor 1 (ESR1) [6], MET [39], NOTCH 3 [6, 39], HDAC4 [27], Gadd45 $\beta$ [40], and Connexin 43 (Cx43) [14, 15, 41]. Among these targets, Cx43 is a well-defined target molecule of miR-206 in many types of cells, including smooth muscle cells [14], myocardial cells [15], type II alveolar epithelial cells [15] and breast cancer cells [16]. Cx43 is ubiquitous in cells and is reduced in a variety of tumor cells [16]. It influences the response of tumor cells to treatments by facilitating the passage of antitumor drugs or death signals between neighboring tumor cells $[17,42]$. Cx43 increased the susceptibility to cisplatin-induced cell death in several tumor types, including melanoma [42], breast cancer [42], adenocarcinoma of the lung [43] and ovarian cancer [44]. In ovarian cancer, Sanjeevani showed that downregulation of Cx43 in A2780s cells decreased the cytotoxicity caused by high-dose cisplatin treatment, and $\mathrm{Cx} 43$ enhanced cisplatin cytotoxicity by propagating the "toxic" signals among coupled cancer cells [17]. In this study, we found that upregulation of miR-206 significantly downregulated the expression of $\mathrm{Cx} 43$ in EOC cell lines, which confirmed the targeting relationship between $\mathrm{Cx} 43$ and miR-206 in EOC. We also found that Cx43 expression was significantly increased in parental cisplatin-sensitive A2780s and OV2008 cells but reduced in the cisplatinresistant $\mathrm{A} 2780 \mathrm{CP}$ and $\mathrm{C} 13$ cells. Survival analysis of data from TCGA by KmPlot showed that high Cx43 miRNA expression was associated with better overall survival in patients who received platinum chemotherapy. These data suggested that miR-206 promotes platinum resistance at least partly by downregulating $\mathrm{Cx} 43$, which in turn reduces the propagating toxic signals among EOC cells and increases cell survival.

There may be some possible limitations in this study. Korch et al. reported that OV2008 used in some labs was a mislabeled version of the HPV-positive ME-180 cell line [45]. We have done experiments using OV2008 cell line since before 2004 [2, 46-48], but we didn't retest the identity of the cell line in our lab stocks to make sure it is the "true" HPV-negative 2008 ovarian cancer cell line defined in the report from Korch et al. [45].

\section{Conclusion}

In the present study, we found that high expression of miR-206 predicted platinum resistance and poor prognosis in patients with EOC. miR-206 functionally enhanced platinum resistance in EOC cells. We believe that the miRNA-206 expression profile, either alone or in conjunction with those of other miRNAs, can be used as a novel biomarker to direct adjuvant chemotherapy in patients with EOC prior to treatment. Targeting miR-206 may be a possible way to reverse the cisplatin resistance of EOC.

\section{Supplementary information}

Supplementary information accompanies this paper at https://doi. org/10.1186/s12935-020-01623-y.

Additional file 1: Fig S1. Kaplan-Meier plots showing the overall survival of patients with ovarian cancer according to the expression of miR-206. (a) Overall survival curves are plotted for all ovarian cancer patients of different races. (b) Overall survival curves are plotted for patients with different ovarian cancer mutation burdens.

Additional file 2: Table S1. MicroRNAs profile that differently expressed in $C R$ and IR.

\section{Acknowledgments}

Not applicable.

\section{Authors' contributions}

Conceived and designed the experiments: SC; Performed the experiments: XZ, GW, YD, JZ, BW, XY, HL; Statistical analysis: XY, XZ, GW; Wrote the paper: $X Y, S C$. Project administration: SC, YD. All authors read and approved the final manuscript.

\section{Funding}

This work was supported by grants from the National Basic Research Program of China (973 Program) [grant numbers 2012CB517600 and 2012CB517603] 
and the Chinese Ministry of Science and Technology Project [grant number 2008DFA30720].

\section{Availability of data and materials}

The datasets used and/or analyzed during the current study are available from the corresponding author on reasonable request.

\section{Ethics approval and consent to participate}

The present study and experimental procedures were approved by the Institutional Review Board of the Ministry of Science and Technology of China, the Human Resource Management Office (Beijing, China) and the ethics committee of the Dalian Medical University (Dalian, China). Written informed consent was obtained from all patients or patients' families. The study was conducted according to the principles outlined in the Declaration of Helsinki.

\section{Consent for publication}

All authors read the final manuscript and agreed to publish it.

\section{Competing interests}

The authors declare that they have no competing interests.

\section{Author details}

1 Department of Pathology and Forensic Medicine, College of Basic Medicine Sciences, Dalian Medical University, No 9 LvShun South Road-W, Dalian 116044, China. ${ }^{2}$ Department of Histology and Embryology, Dalian Medical University, College of Basic Medicine Sciences, No 9 LvShun South Road-W, Dalian 116044, China. ${ }^{3}$ Cancer Stem Cell Institute, Dalian Medical University, No 9 LvShun South Road-W, Dalian 116044, China.

Received: 14 July 2020 Accepted: 26 October 2020

Published online: 03 November 2020

\section{References}

1. van Zyl B, Tang D, Bowden NA. Biomarkers of platinum resistance in ovarian cancer: what can we use to improve treatment. Endocr Relat Cancer. 2018;25(5):R303-18.

2. Zhao H, Yu X, Ding Y, Zhao J, Wang G, Wu X, Jiang J, Peng C, Guo GZ, Cui S. MiR-770-5p inhibits cisplatin chemoresistance in human ovarian cancer by targeting ERCC2. Oncotarget. 2016;7(33):53254-68.

3. Zheng H, Liu JY, Song FJ, Chen KX. Advances in circulating microRNAs as diagnostic and prognostic markers for ovarian cancer. Cancer Biol Med. 2013;10(3):123-30.

4. Alberts DS, Green S, Hannigan EV, O'Toole R, Stock-Novack D, Anderson P, Surwit EA, Malvlya VK, Nahhas WA, Jolles CJ. Improved therapeutic index of carboplatin plus cyclophosphamide versus cisplatin plus cyclophosphamide: final report by the Southwest Oncology Group of a phase III randomized trial in stages III and IV ovarian cancer. J Clin Oncol. 1992;10(5):706-17.

5. Bartel DP. MicroRNAs: genomics, biogenesis, mechanism, and function. Cell. 2004;116(2):281-97.

6. Nohata N, Hanazawa T, Enokida H, Seki N. microRNA-1/133a and microRNA-206/133b clusters: dysregulation and functional roles in human cancers. Oncotarget. 2012;3(1):9-21.

7. Ling H, Fabbri M, Calin GA. MicroRNAs and other non-coding RNAs as targets for anticancer drug development. Nat Rev Drug Discov. 2013;12(11):847-65.

8. Heneghan HM, Miller N, Kerin MJ. Circulating miRNA signatures: promising prognostic tools for cancer. J Clin Oncol. 2010; 28(29):e573-4; author reply e575-6.

9. Rustin GJ, Nelstrop AE, McClean P, Brady MF, McGuire WP, Hoskins WJ, Mitchell H, Lambert HE. Defining response of ovarian carcinoma to initial chemotherapy according to serum CA 125. J Clin Oncol. 1996;14(5):1545-51.

10. Zhao H, Liu S, Wang G, Wu X, Ding Y, Guo G, Jiang J, Cui S. Expression of miR-136 is associated with the primary cisplatin resistance of human epithelial ovarian cancer. Oncol Rep. 2015;33(2):591-8.

11. Flate E, Stalvey JR. Motility of select ovarian cancer cell lines: effect of extra-cellular matrix proteins and the involvement of PAK2. Int J Oncol. 2014;45(4):1401-11.
12. Hallas-Potts A, Dawson JC, Herrington CS. Ovarian cancer cell lines derived from non-serous carcinomas migrate and invade more aggressively than those derived from high-grade serous carcinomas. Sci Rep. 2019;9(1):5515.

13. Nagy A, Lanczky A, Menyhart O, Gyorffy B. Validation of miRNA prognostic power in hepatocellular carcinoma using expression data of independent datasets. Sci Rep. 2018;8(1):9227.

14. Li H, Xiang Y, Fan LJ, Zhang XY, Li JP, Yu CX, Bao LY, Cao DS, Xing WB, Liao $\mathrm{XH}$, et al. Myocardin inhibited the gap protein connexin 43 via promoted miR-206 to regulate vascular smooth muscle cell phenotypic switch. Gene. 2017;616:22-30.

15. Zhou J, Fu Y, Liu K, Hou L, Zhang W. miR-206 regulates alveolar type II epithelial cell Cx43 expression in sepsis-induced acute lung injury. Exp Ther Med. 2019;18(1):296-304.

16. Fu Y, Shao ZM, He QZ, Jiang BQ, Wu Y, Zhuang ZG. Hsa-miR-206 represses the proliferation and invasion of breast cancer cells by targeting Cx43. Eur Rev Med Pharmacol Sci. 2015;19(11):2091-104.

17. Arora S, Heyza JR, Chalfin EC, Ruch RJ, Patrick SM. Gap junction intercellular communication positively regulates cisplatin toxicity by inducing DNA damage through bystander signaling. Cancers. 2018;10(10):368.

18. Zhao H, Bi T, Qu Z, Jiang J, Cui S, Wang Y. Expression of miR-224-5p is associated with the original cisplatin resistance of ovarian papillary serous carcinoma. Oncol Rep. 2014;32(3):1003-12.

19. Yang N, Kaur S, Volinia S, Greshock J, Lassus H, Hasegawa K, Liang S, Leminen A, Deng S, Smith L, et al. MicroRNA microarray identifies Let-7i as a novel biomarker and therapeutic target in human epithelial ovarian cancer. Can Res. 2008;68(24):10307-14.

20. Eitan R, Kushnir M, Lithwick-Yanai G, David MB, Hoshen M, Glezerman M, Hod M, Sabah G, Rosenwald S, Levavi H. Tumor microRNA expression patterns associated with resistance to platinum based chemotherapy and survival in ovarian cancer patients. Gynecol Oncol. 2009;114(2):253-9.

21. Yang L, Li N, Wang H, Jia X, Wang X, Luo J. Altered microRNA expression in cisplatin-resistant ovarian cancer cells and upregulation of miR-130a associated with MDR1/P-glycoprotein-mediated drug resistance. Oncol Rep. 2012;28(2):592-600.

22. Chan JK, Blansit K, Kiet T, Sherman A, Wong G, Earle C, Bourguignon LY. The inhibition of miR-21 promotes apoptosis and chemosensitivity in ovarian cancer. Gynecol Oncol. 2014;132(3):739-44.

23. Zou J, Yin F, Wang Q, Zhang W, Li L. Analysis of microarray-identified genes and microRNAs associated with drug resistance in ovarian cancer. Int J Clin Exp Pathol. 2015:8(6):6847-58.

24. van Jaarsveld MT, Helleman J, Boersma AW, van Kuijk PF, van ljcken WF, Despierre E, Vergote I, Mathijssen RH, Berns EM, Verweij J, et al. miR-141 regulates KEAP1 and modulates cisplatin sensitivity in ovarian cancer cells. Oncogene. 2013;32(36):4284-93.

25. Sorrentino A, Liu CG, Addario A, Peschle C, Scambia G, Ferlini C. Role of microRNAs in drug-resistant ovarian cancer cells. Gynecol Oncol. 2008;111(3):478-86.

26. Ma G, Wang Y, Li Y, Cui L, Zhao Y, Zhao B, Li K. MiR-206, a key modulator of skeletal muscle development and disease. Int J Biol Sci. 2015;11(3):345-52.

27. Mitchelson KR, Qin WY. Roles of the canonical myomiRs miR-1, -133 and -206 in cell development and disease. World J Biol Chem. 2015;6(3):162-208.

28. Watt K, Newsted D, Voorand E, Gooding RJ, Majewski A, Truesdell P, Yao B, Tuschl T, Renwick N, Craig AW. MicroRNA-206 suppresses TGF-beta signalling to limit tumor growth and metastasis in lung adenocarcinoma. Cell Signal. 2018;50:25-36.

29. Kondo N, Toyama T, Sugiura H, Fujii Y, Yamashita H. miR-206 Expression is down-regulated in estrogen receptor alpha-positive human breast cancer. Can Res. 2008;68(13):5004-8.

30. Zhou Y, Wang M, Tong Y, Liu X, Zhang L, Dong D, Shao J, Zhou Y. miR-206 promotes cancer progression by targeting full-length neurokinin-1 receptor in breast cancer. Technol Cancer Res Treatment. 2019;18:1533033819875168.

31. Shi J, Zhang D, Zhong Z, Zhang W. IncRNA ROR promotes the progression of renal cell carcinoma through the miR206/VEGF axis. Mol Med Rep. 2019;20(4):3782-92.

32. Chen X, Yan Q, Li S, Zhou L, Yang H, Yang Y, Liu X, Wan X. Expression of the tumor suppressor miR-206 is associated with cellular proliferative 
inhibition and impairs invasion in ERalpha-positive endometrioid adenocarcinoma. Cancer Lett. 2012;314(1):41-53.

33. Wang Y, Tai Q, Zhang J, Kang J, Gao F, Zhong F, Cai L, Fang F, Gao Y. MiRNA-206 inhibits hepatocellular carcinoma cell proliferation and migration but promotes apoptosis by modulating CMET expression. Acta Biochim Biophys Sin. 2019;51(3):243-53.

34. Yang $Q$, Zhang L, Zhong Y, Lai L, Li X. miR-206 inhibits cell proliferation, invasion, and migration by down-regulating PTP1B in hepatocellular carcinoma. Biosci Rep. 2019:39(5):BSR20181823.

35. Zhou F, Cao W, Xu R, Zhang J, Yu T, Xu X, Zhi T, Yin J, Cao S, Liu N, et al. MicroRNA-206 attenuates glioma cell proliferation, migration, and invasion by blocking the WNT/beta-catenin pathway via direct targeting of Frizzled 7 mRNA. Am J Transl Res. 2019;11(7):4584-601.

36. Quan Y, Huang X, Quan X. Expression of miRNA-206 and miRNA145 in breast cancer and correlation with prognosis. Oncol Lett. 2018;16(5):6638-42.

37. Du G, Zhou J, Cheng L, Ma X, Gui Y, Tan B. High expression of mir206 predicts adverse outcomes: a potential therapeutic target for esophageal cancer. Combinatorial Chem High Throughput Screening. 2019:22(9):599-611.

38. Mihaly D, Papp G, Mervai Z, Reszegi A, Tatrai P, Szaloki G, Sapi J, Sapi Z. The oncomir face of microRNA-206: a permanent miR-206 transfection study. Exp Biol Med (Maywood, NJ). 2018;243(12):1014-23.

39. Liu W, Xu C, Wan H, Liu C, Wen C, Lu H, Wan F. MicroRNA-206 overexpression promotes apoptosis, induces cell cycle arrest and inhibits the migration of human hepatocellular carcinoma HepG2 cells. Int J Mol Med. 2014;34(2):420-8.

40. Zhai C, Qian Q, Tang G, Han B, Hu H, Yin D, Pan H, Zhang S. MicroRNA-206 protects against myocardial ischaemia-reperfusion injury in rats by targeting Gadd45beta. Mol Cells. 2017;40(12):916-24.

41. Lin ZJ, Ming J, Yang L, Du JZ, Wang N, Luo HJ. Mechanism of regulatory effect of microRNA-206 on connexin 43 in distant metastasis of breast cancer. Chin Med J. 2016;129(4):424-34.
42. Chang WW, Lai CH, Chen MC, Liu CF, Kuan YD, Lin ST, Lee CH. Salmonella enhance chemosensitivity in tumor through connexin 43 upregulation. Int J Cancer. 2013;133(8):1926-2135.

43. Yu M, Zhang C, Li L, Dong S, Zhang N, Tong X. CX43 reverses the resistance of A549 lung adenocarcinoma cells to cisplatin by inhibiting EMT. Oncology reports. 2014;31(6):2751-8.

44. Gavin EJ, Song B, Wang Y, Xi Y, Ju J. Reduction of Orc6 expression sensitizes human colon cancer cells to 5-fluorouracil and cisplatin. PLOS ONE. 2008;3(12):e4054.

45. Korch C, Spillman MA, Jackson TA, Jacobsen BM, Murphy SK, Lessey BA, Jordan VC, Bradford AP. DNA profiling analysis of endometrial and ovarian cell lines reveals misidentification, redundancy and contamination. Gynecol Oncol. 2012;127(1):241-8.

46. Xu G, Zhong Y, Munir S, Yang BB, Tsang BK, Peng C. Nodal induces apoptosis and inhibits proliferation in human epithelial ovarian cancer cells via activin receptor-like kinase 7. J Clin Endocrinol Metab. 2004;89(11):5523-34.

47. Xu G, Zhou H, Wang Q, Auersperg N, Peng C. Activin receptor-like kinase 7 induces apoptosis through up-regulation of Bax and down-regulation of Xiap in normal and malignant ovarian epithelial cell lines. Mol Cancer Res. 2006;4(4):235-46.

48. Ye G, Fu G, Cui S, Zhao S, Bernaudo S, Bai Y, Ding Y, Zhang Y, Yang BB, Peng C. MicroRNA 376c enhances ovarian cancer cell survival by targeting activin receptor-like kinase 7: implications for chemoresistance. J Cell Sci. 2011;124(Pt 3):359-68.

\section{Publisher's Note}

Springer Nature remains neutral with regard to jurisdictional claims in published maps and institutional affiliations.
Ready to submit your research? Choose BMC and benefit from:

- fast, convenient online submission

- thorough peer review by experienced researchers in your field

- rapid publication on acceptance

- support for research data, including large and complex data types

- gold Open Access which fosters wider collaboration and increased citations

- maximum visibility for your research: over $100 \mathrm{M}$ website views per year

At BMC, research is always in progress.

Learn more biomedcentral.com/submissions 